17. Roda A, Cappelleri G, Aldini R, Roda E. Barbara L 1982 Quantitative aspects of the interaction of bile acids with human serum albumin. J Lipid Res 23:490-495

18. Roda A, Roda E, Aldini R, Festi D, Mazzella G, Sama C, Barbara L 1977 Development, validation and application of a single-tube radioimmunoassay for cholic and chenodeoxycholic conjugated bile acids in human serum. Clin Chem 23:2107-2113

19. Roda A, Roda E, Festi D, Aldini R, Mazzella G, Sama C, Barbara L 1978 A radioimmunoassay for lithocholic acid conjugates in human serum and liver tissue. Steroids 32:13-19

20. Sewell RB, Hardy KJ, Smallwood RA, Hoffman NE 1980 Fetal bile salt metabolism: placental transfer of taurocholate in sheep. Am J Physiol 239:G354-357

21. Sewell RB. Hardy KJ, Smallwood RA. Hoffman NE 1982 Fetal bile salt metabolism: placental transfer of dihydroxy bile salts in sheep. Am J Physiol 6:G172-175

22. Strange RC. Hume R, Eadington DW. Nisumo IA 1981 Distribution of glycocholate in blood from human fetuses and adults. Pediatr Res 15:14251428

23. Suchy FJ, Balistreri WF 1980 Maturation of bile acid conjugation in hepato- cytes isolated from fetal and sucking rats. Gastroenterology 78:1324 (abstr)

24. Suchy FJ, Balistreri WF 1982 Uptake of taurocholate of hepatocytes isolated from developing rats. Pediatr Res 16:282-285

25. Suchy FJ, Balistreri WF, Heubi JE, Searchy JE, Levin RS 1981 Physiologic cholestasis: elevation of the primary serum bile acid concentrations in normal infants. Gastroenterology 80:1037-1041

26. Suchy FJ, Heubi JE, Balistreri WF, Belknap WM 1981 The enterohepatic circulation of bile acids in suckling and weanling rats. Gastroenterology 80:1351 (abstr)

27. Tikanoja T, Tikanoja S, Simell O 1981 Plasma conjugated cholic acid in premature and term newborns and young infants. Acta Pediatr Scand 70:491-495

28. Vlahcevik ZR, Schwartz CC, Gustafsson J, Halloran LG, Danielsson H, Swell L 1980 Biosynthesis of bile acids in man. Multiple pathways to cholic and chenodeoxycholic acid. J Biol Chem 255:2925-2933

29. Watkins JB, Goldstein E, Coryer R, Brown ER, Eraklis A 1979 Sulfation of bile acids in the fetus. In: Presig R, Bircher J (eds) The Liver Quantitative Aspects of Structure and Function. Editio Cantor, Aulendorf, pp 249-254

30. Watkins JB 1983 Placental transport: bile acid conjugation and sulfation in the fetus. J Pediatr Gastroenterol Nutr 2:365-373

\title{
Effect of Postnatal Anoxia on Bilirubin Levels in Rat Brain
}

\author{
FEDERICO MAYOR, JR., MONSERRAT PAGÉS, JAVIER DIEEZ-GUERRA, \\ FERNANDO VALDIVIESO, AND FEDERICO MAYOR \\ Departamento de Bioquimica y Biologia Molecular, Centro de Biologia Molecular, Facultad de Ciencias, \\ Universidad Autónoma, Madrid, Spain
}

\begin{abstract}
The effects of a period of anoxia 18-24 h after birth on bilirubin levels in rat brain were investigated during anoxia, recovery, and development. Postnatal anoxia induces a significant, temporary increase (up to $200 \%$ with respect to control values) in newborn rat brain bilirubin levels during anoxia and short-term recovery. Pretreatment of the newborn rats with a single dose of the drug sulfixosazole markedly enhances bilirubin accumulation in the brain of the anoxic rats. A second rise in brain bilirubin concentration is detected in a group of the newborn rats 3-6 days after oxygen deprivation. Autoradiographic localization of radiolabeled bilirubin following in vivo experiments suggests that this substance is preferentially accumulated in some areas of the newborn rat brain as a consequence of postnatal anoxia, and indicates, together with the effect of sulfixosazole, that as a result of anoxia, a displacement of unbound bilirubin from blood to the nervous tissue occurs. Our results confirm the importance of anoxia as a risk factor for the development of bilirubin-induced encephalopathy. The possible relevance of intracerebral hemorrhages caused by perinatal asphyxia producing delayed bilirubin accumulation in the newborn rat brain is suggested. (Pediatr Res 19: 231-236, 1985)
\end{abstract}

Received May 16, 1984; accepted July 11, 1984

Correspondence Prof. F. Mayor, Departmento de Bioquimica y Biologia Molecular, Centro de Biologia Molecular, Facultad de Ciencias, Universidad Autónoma de Madrid, Madrid-34, Spain.

This work was supported by a grant from the Comision Asesora de Investigacion Cientifica y Técnica (Ministry of Science and Education of Spain).
Despite the current development of neonatology and the use of exchange transfusion and phototherapy, kernicterus continues to occur, specially in sick, premature, or low birth weight babies, as has been recently pointed out by different reports $(20,31,36)$. Despite the various diagnostic and therapeutic measures intended to prevent bilirubin encephalopathy, at present no blood chemistry value (including bilirubin concentration) or clinical factors can completely predict the risk of kernicterus.

Perinatal asphyxia, together with prematurity, acidosis, respiratory distress syndrome, and the use of certain drugs have been reported to be the major predisposing risk factors for the occurrence of bilirubin encephalopathy in newborn infants with low levels of serum bilirubin $(1,6,15,20,43)$. These clinical reports, together with the fact that the neurological damage associated with perinatal asphyxia or anoxia shows brain regional distribution and clinical manifestations somewhat similar to those observed in bilirubin encephalopathy $(9,27,29)$, have prompted us to investigate the relationship between episodes of lack of oxygen in the postnatal period and the accumulation of bilirubin in the brain.

\section{MATERIALS AND METHODS}

Chemicals. $1^{\prime}, 2,3^{\prime}, 4,5,6{ }^{\prime}, 7^{\prime}, 8\left[{ }^{14} \mathrm{C}\right]$ bilirubin $(62.5 \mathrm{mCi} /$ mmol) was obtained from The Radiochemical Centre, Amersham, Bucks, UK. Sulfixosazole and bilirubin were purchased from Sigma Chemical Co., St. Louis, MO. All other reagents used were of the highest purity available.

Animals. Dated pregnant rats of the Wistar strain weighing 
$250 \mathrm{~g}$ were individually caged and fed on standard laboratory food and water ad libitum. The time of birth was noted within 4 h. Pups were born vaginally and reared with their dams until 18-24 h after birth.

Anoxia. The experimental animals (18-24 h of postnatal age) were rendered anoxic for periods up to $20 \mathrm{~min}$, essentially as previously described (37). Groups of four to six newborn rats were placed in 500-ml glass jars. The jars were stoppered except for small intake and outlet taps, and partially immersed in a $37^{\circ}$ $\mathrm{C}$ water bath to maintain a constant thermal environment. Anoxia was achieved by bubbling $100 \%$ nitrogen at a rate of $4-$ $6 \mathrm{liter} / \mathrm{min}$ through water at $37^{\circ} \mathrm{C}$ and delivering the gas into the $500-\mathrm{ml}$ jars. In this experimental model, the oxygen tension of the effluent gas was less than $0.03 \mathrm{~mm} \mathrm{Hg}$, and total anoxemia is obtained within 2 min after exposure to nitrogen (11). The control newborns were exposed, under the same conditions, to humidified air. Littermates were removed after 5,10 , or $20 \mathrm{~min}$ of anoxia and then immediately frozen in liquid $\mathrm{N}_{2}$. Other animals rendered anoxic for $20 \mathrm{~min}$ were allowed to recover in air at $37^{\circ} \mathrm{C}$. In the short-term recovery experiments, the surviving newborns (approximately $80 \%$ ) were kept at $37^{\circ} \mathrm{C}$ for different intervals prior to freezing in liquid $\mathrm{N}_{2}$. In the long-term experiments the survivors, after a $1-\mathrm{h}$ period of recovery at $37^{\circ} \mathrm{C}$, were returned to their mothers, whose litters were normalized to $8-$ 10 pups, and kept with them for 1-7 days. When required, the pups were sacrificed by immersion in liquid $\mathrm{N}_{2}$. From the time of freezing until use, animal carcasses were stored at $-80^{\circ} \mathrm{C}$.

In some experiments, newborn rats were pretreated $30 \mathrm{~min}$ before the onset of the anoxic episode either with $600 \mu \mathrm{g} / \mathrm{g}$ sulfixosazole administered subcutaneously or with $9 \mu \mathrm{g} / \mathrm{g}$, bilirubin injected intraperitoneally with a 100- $\mu$ l Hamilton syringe equipped with a $1 / 3-\mathrm{mm}$ gauge needle (Hamilton Co., Reno, NV). Control animals received the same volume of $0.9 \%(\mathrm{w} / \mathrm{v}) \mathrm{NaCl}$. Bilirubin solutions were prepared by dissolving crystalline bilirubin in a small volume of $0.1 \mathrm{M} \mathrm{NaOH}$, diluting with saline, and adjusting the $\mathrm{pH}$ to 8 (25).

Determination of brain bilirubin levels. Whole-brain bilirubin levels in individual control and anoxic newborn rats were determined as previously described (34). Brain tissue was homogenized with 3 volumes of $0.25 \mathrm{M}$, sucrose solution. The extraction mixture containing $1 \mathrm{ml}$ tissue homogenate, $4 \mathrm{ml}$ distilled water, $5 \mathrm{ml}$ chloroform, and $12 \mathrm{ml}$ methanol was homogenized. After adding $8 \mathrm{ml}$ distilled water the whole mixture was centrifuged for $30 \mathrm{~min}$ at $10000 \times \mathrm{g}$. The procedure was carried out in dim light below $4^{\circ} \mathrm{C}$. Bilirubin in the chloroform phase was determined directly from the difference between the absorbance at 452 and $490 \mathrm{~nm}$ on a Pye-Unicam SP-1700 double-beam spectrophotometer, using commercial bilirubin as a standard. For the determination of brain bilirubin levels in 1-day-old rats, the forebrains of two newborn rats were pooled.

Analysis of the data. Statistical analysis was performed by the Student's $t$ test for nonpaired samples and comparison was made with the control group. $p$ values of 0.05 or less were taken as significant, and the results are expressed as the mean \pm SEM.

Autoradiography. One-day-old rats were used. Immediately after 20 -min exposure to $100 \%$ nitrogen, $2 \mu \mathrm{Ci}$ of $\left[{ }^{14} \mathrm{C}\right]$ bilirubin were administered intraperitoneally into the anoxic and control rats in $100 \mu \mathrm{l}$ of $0.9 \%$ saline. Thirty minutes later, the animals were sacrificed by decapitation and the brains rapidly removed and fixed in $10 \%$ formalin. Four- to five-millimeter slices of appropriate regions were cut. Following repeated washings in ethanol and xylol the tissue was embedded in paraffin and multiple serial sections, 3-4 $\mu \mathrm{m}$ in thickness, were obtained on an microtome and mounted onto subbed slides. The paraffin was removed by washing with xylol (two 10-min rinses). Finally, the slides were covered with AR-10 autoradiographic stripping film (Eastman Kodak, Rochester, NY), air dried, and placed in light-tight boxes. The tissue sections were developed after an exposure of $10-12 \mathrm{wk}$ at $4^{\circ} \mathrm{C}$ and examined microscopically under dark-field and bright-field illumination. In some cases, computer-generated densitometric maps were obtained by measuring the optical density of the radioactively exposed film with the aid of a microdensitometer (Photomation System P-1700, Optronics International Inc., Chelmsford, MA) connected by means of an Assembler language to a PDP 11/45 computer (Digital Equipment Corp., Maynard, MA) with a Fortran IV language. The image was digitalized, the optical densities coded into 9 gray tones, and the densitometric map printed by the computer using a Varian printer-plotter. A similar method of image analysis has been recently published (14). For the in vitro autoradiographic studies, the brain sections were prepared and incubated for $30 \mathrm{~min}$ with $0.4 \mu \mathrm{M}$ radioactive bilirubin in 120

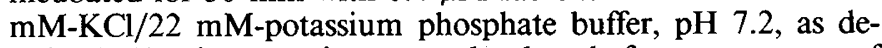
scribed. The tissue sections were developed after an exposure of 20-30 days, and the slides viewed by both bright-field and darkfield microscopy. Under these conditions, the autoradiographic technique provides quantitative data because autoradiographic grain densities are proportional to time of exposure and tissue content of radioactivity (44).

\section{RESULTS}

The effect of postnatal (18-24 h of age) exposure to nitrogen atmosphere on rat brain bilirubin levels during anoxia and the first $6 \mathrm{~h}$ of recovery is shown in Figure 1. The brain bilirubin levels in the control littermates remained constant throughout the experimental period and are similar to those previously reported (34). During the first $5 \mathrm{~min}$ of anoxia, brain bilirubin levels increased abruptly and reached a maximum at $35-50 \mathrm{~min}$ (15-30 min of recovery). As recovery continued, a gradual decrease in brain bilirubin levels was observed in the anoxic newborns.

In order to investigate whether postnatal anoxia (on the 1st day of life) has any long-term effect on rat brain bilirubin levels, groups of rats that survived a 20-min anoxic episode were returned to their dams and kept with them for up to 8 days of life (i.e. for up to 7 days after exposure to anoxia). Brain bilirubin concentrations were determined at different ages and compared to those of control littermates. The results are shown in Table 1. No significative changes in brain bilirubin levels were observed in the control rats during the developmental period studied. A significant increase in brain bilirubin concentration in the anoxic rats was detected at 4-7 days of age (3-6 days after the anoxic episode). By day 8 , the brain bilirubin levels in the treated group were restored to control values.

It should be mentioned that this rise in brain bilirubin concentration shows an interesting difference with respect to that observed during anoxia and short-term recovery (see Fig. 1). In the latter case, all newborns subjected to anoxia experienced an increase in their brain bilirubin content, with narrow differences between individual values for a given period of anoxia or recovery. On the other hand, the individual brain bilirubin levels of the anoxic group at 4-7 days of age differ considerably. Whereas some animals show values indistinguishable from those of control rats, others have a higher accumulation of bilirubin in brain, with a wide range of levels. For instance, at 5 days of life, when the mean brain bilirubin level for the anoxic group (18 animals) was $0.355 \pm 0.052$ (significantly higher than control rats), seven treated rats showed values similar to those of controls, whereas $11(60 \%)$ exhibit a wide range (up to $0.9 \mu \mathrm{g}$ bilirubin/g wet weight) of brain bilirubin concentrations more than $0.25 \mu \mathrm{g} / \mathrm{g}$ wet weight, a value never reached by control rats throughout the experimental period.

In order to understand the mechanism by which postnatal anoxia induces an increase in brain bilirubin levels more clearly, we studied the effect of different pretreatments of newborn rats on brain bilirubin concentrations during the first period of recovery from 20 -min postnatal anoxia (see Table 2). Pretreatment with a single dose of sulfixosazole-a drug known to displace serum albumin-bound bilirubin, increasing the blood 


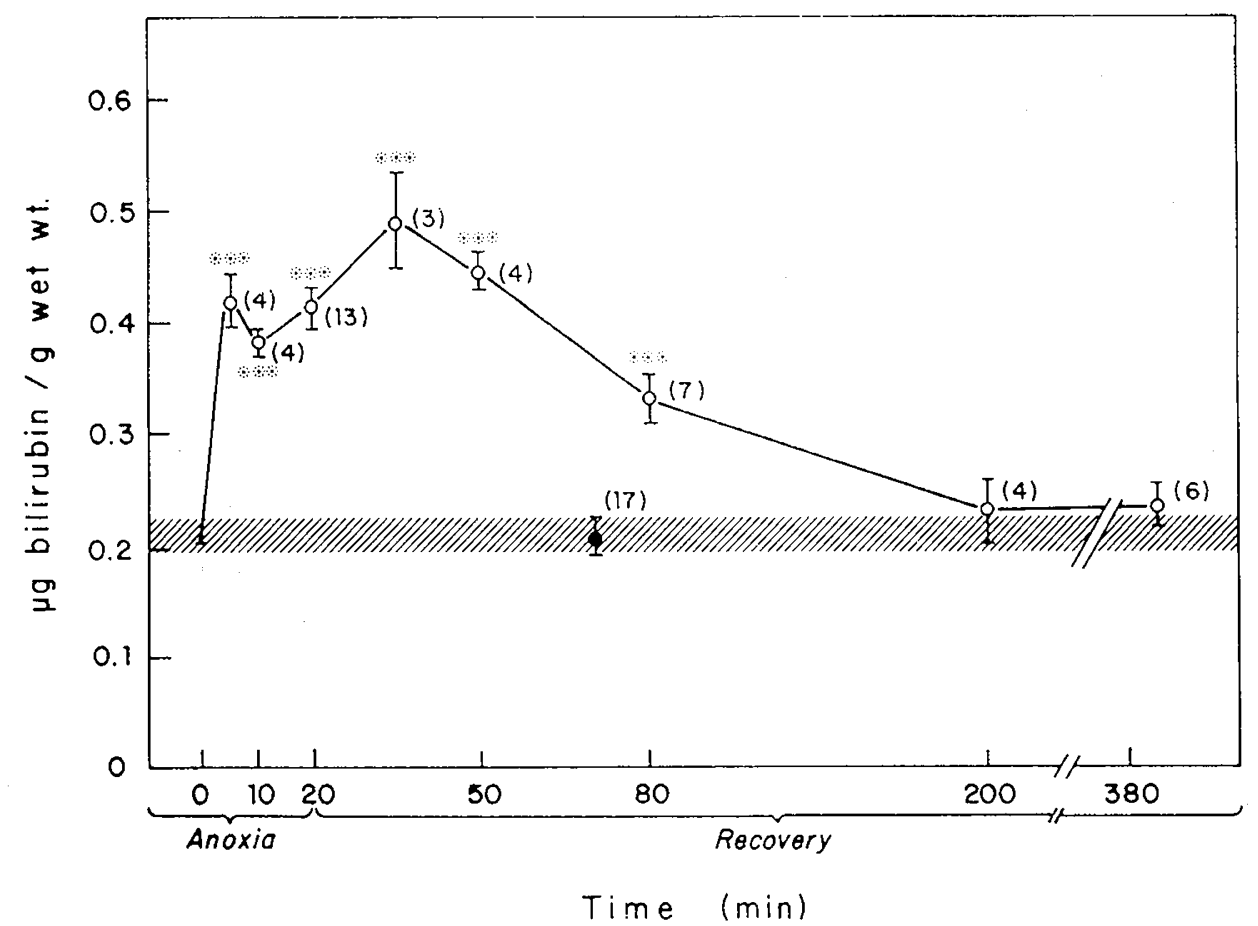

Fig. 1. Brain bilirubin levels during anoxia and recovery. Whole-brain bilirubin levels, expressed as $\mu \mathrm{g} / \mathrm{g}$ brain wet weight were determined in the anoxic $(O)$ and control $(\Theta)$ neonatal rats. The brains of two animals were pooled for each determination. The results are the means \pm SEM of the number of determinations shown in parentheses. The dashed area denotes mean control values $\pm \operatorname{SEM}^{* * *} p<0.001$ for comparison of anoxic and control newborns.

Table 1. Effect of postnatal anoxia on bilirubin levels in rat brain during development

\begin{tabular}{ccc}
\hline & \multicolumn{2}{c}{ Brain bilirubin levels $(\mu \mathrm{g} / \mathrm{g}$ wet wt) } \\
\cline { 2 - 3 } Age (days) & Control rats & \multicolumn{1}{c}{ Anoxic rats } \\
\hline 2 & $0.181 \pm 0.010(3)$ & $0.190 \pm 0.015(6)$ \\
3 & $0.156 \pm 0.018(7)$ & $0.176 \pm 0.017(14)$ \\
4 & $0.161 \pm 0.018(6)$ & $0.270 \pm 0.044(6)^{*}$ \\
5 & $0.162 \pm 0.023(6)$ & $0.355 \pm 0.052(18)^{*}$ \\
6 & $0.190 \pm 0.008(7)$ & $0.262 \pm 0.022(10)^{* *}$ \\
7 & $0.158 \pm 0.024(3)$ & $0.286 \pm 0.037(6)^{*}$ \\
8 & $0.164 \pm 0.012(3)$ & $0.194 \pm 0.009(7)$ \\
\hline
\end{tabular}

The newborn rats were rendered anoxic for $20 \mathrm{~min}$. The surviving anoxic rats and the control littermates were reared for up to 8 days of life with their dams. The results are the means \pm SEM of the number of animals shown in parentheses. ${ }^{*} p<0.05,{ }^{* *} p<0.01$ for comparison of anoxic and control neonates of the same age.

levels of unbound, "free" bilirubin (3)-by itself promotes a significant rise $(p<0.001)$ in brain bilirubin levels in comparison with control rats, although the bilirubin concentration reached is less than that detected after a period of 20 min anoxia (see Fig. 1). On the other hand, pretreatment with sulfixosazole significantly enhanced $(p<0.05)$ the increase in brain bilirubin levels observed after $30 \mathrm{~min}$ of recovery from a 20 -min anoxic episode. The bilirubin accumulation rose to $0.622 \pm 0.057 \mu \mathrm{g} / \mathrm{g}$ of brain wet weight, approximately three times the control values, and was also significantly higher $(p<0.05)$ than those detected in animals injected with sulfixosazole, but not subjected to anoxia.

Unlike sulfixosazole, pretreatment with a single dose of bilirubin prior to anoxia did not significantly enhance the increase in brain bilirubin levels induced by postnatal anoxia under our experimental conditions. However, bilirubin pretreatment seems to slow down the gradual decrease in brain bilirubin observed in the anoxic rats after the first $30 \mathrm{~min}$ of recovery. Thus, brain bilirubin values at 180 min of recovery in the bilirubin-pretreated group were significantly higher $(p<0.01)$ than those of control
Table 2. Effect of different treatments on brain bilirubin levels in newborn rats

\begin{tabular}{|c|c|c|c|}
\hline & \multicolumn{2}{|l|}{ Treatment } & \multirow[b]{2}{*}{$\begin{array}{c}\text { Brain bilirubin level } \\
(\mu \mathrm{g} / \mathrm{g} \text { wet } w \mathrm{t})\end{array}$} \\
\hline Pretreatment & $\begin{array}{c}\text { Exposure } \\
\text { to anoxia } \\
\text { (min) }\end{array}$ & $\begin{array}{c}\text { Recovery } \\
\text { from anoxia } \\
\text { (min) }\end{array}$ & \\
\hline Control & & & $0.212 \pm 0.015(17)$ \\
\hline None & 20 & 30 & $0.446 \pm 0.016(4)^{* *}$ \\
\hline None & 20 & 60 & $0.334 \pm 0.021(7)^{* *}$ \\
\hline None & 20 & 180 & $0.234 \pm 0.019(4)$ \\
\hline Saline $\dagger$ & & & $0.197 \pm 0.037(4)$ \\
\hline Sulfixosazole $\dagger$ & & & $0.358 \pm 0.030(4)^{* *}$ \\
\hline Sulfixosazole $\ddagger$ & 20 & 30 & $0.622 \pm 0.057(11)^{* *}$ \\
\hline Bilirubin $\ddagger$ & 20 & 60 & $0.356 \pm 0.021(14)^{* *}$ \\
\hline Bilirubin $\ddagger$ & 20 & 180 & $0.289 \pm 0.019(7)^{*}$ \\
\hline
\end{tabular}

Brains of two animals were pooled for each determination. The results are the means \pm SEM of the number of determinations shown in parentheses. ${ }^{*} p<0.01^{* *} p<0.001$, for comparison of treatment and control nwborns.

† Brain bilirubin levels were determined $90 \mathrm{~min}$ after the injection.

$\ddagger$ Injected $30 \mathrm{~min}$ before the onset of the anoxic episode.

rats, whereas no significant differences with respect to controls were detected at the same time of recovery in the animals subjected to 20-min anoxia without prior injection of bilirubin.

In another set of experiments, radiolabelled bilirubin was injected to control and 20-min anoxic rats, and the animals sacrified 30 min later, when the maximum level of bilirubin accumulation is reached in the brain of the anoxic animals (see Fig. 1). We have used autoradiographic techniques, detailed in the "Methods and Materials" section, to localize bilirubin distribution in nervous tissue sections examined with the light microscope. No noticeable accumulation of radioactive bilirubin was detected in the brain of control rats, with the radioactive grains located mainly in the brain blood vessels (results not shown). On the other hand, tissue sections from the brain of the anoxic 

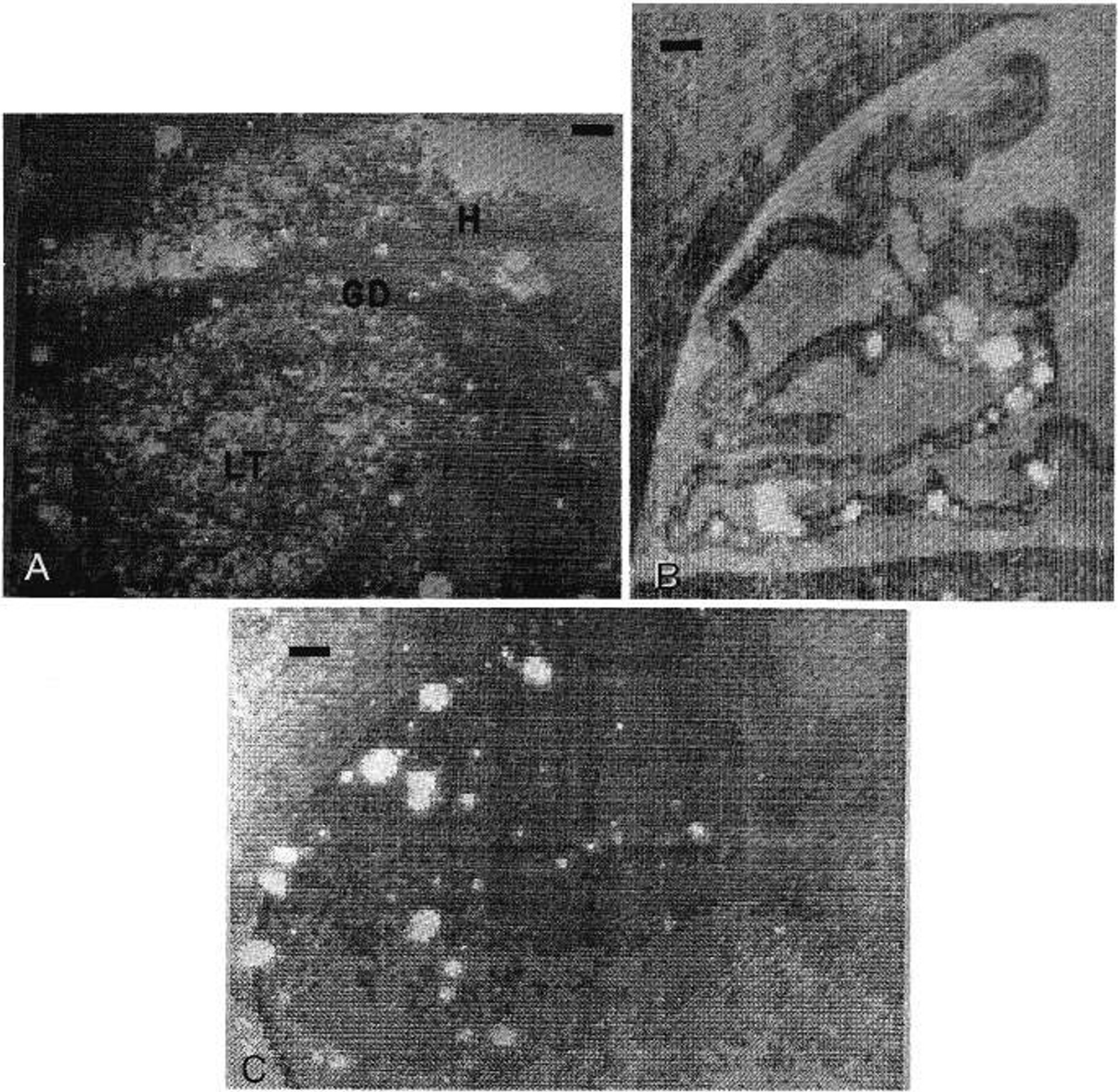

Fig. 2. Autoradiography of in vivo bilirubin distribution in brain areas from anoxic newborn rats. Densitometric maps were printed by a PDP $11 / 45$ computer after image analysis of autoradiograms of $\left[{ }^{14} \mathrm{C}\right]$ bilirubin distribution. The brain section shown in $A$ includes the hippocampus $(H)$, the dentate gyrus $(G D)$, and the lateral nucleus of the thalamus $(L T)$, whereas the densitometric maps $B$ and $C$ show bilirubin distribution at the level of the choroid plexus of the walls of the lateral ventricle and in a cerebral cortex area, respectively. Bar, $150 \mu \mathrm{m}$. The white spots correspond to high densities of $\left[{ }^{14} \mathrm{C}\right]$ bilirubin autoradiographic grains.

newborn animals showed a remarkable presence of autoradiographic grains, indicating a displacement of bilirubin from the blood to the nervous tissue as a result of postnatal anoxia. Furthermore, in examining different areas of the brain, regions with a high density of grains were observed; these include hippocampus, thalamus, some areas of the cerebral cortex, and the choroid plexus of the walls of the lateral ventricle (see Fig. 2). In the two latter regions, radiolabelled bilirubin appeared concentrated in intense, local radioactive spots (Fig. $2 B$ and $C$ ). These results suggest that when bilirubin is accumulated by the newborn rat brain as a consequence of postnatal anoxia, a relatively specific or preferential distribution of the pigment in the nervous tissue occurs.
The regional distribution of bilirubin in brain sections has alsc been studied by autoradiography after experiments in vitro where tissue sections from control and anoxic rats were incubated in the presence of $0.4 \mu \mathrm{M}\left[{ }^{14} \mathrm{C}\right]$ bilirubin (Table 3 ). Under our experimental conditions, bilirubin binds to the cellular structures, with no significant differences between the brain areas examined in the control rats, except the cerebellum, where a slightly higher grain density was found. In the anoxia-treatec rats, higher autoradiographic grain densities than in control rats and than other brain regions of the anoxic rats were detected ir the cerebellum, hippocampus, and striatum. However, no de. fined brain areas for bilirubin accumulation could be detectec by this method. 
Table 3. Regional distribution of radioactive bilirubin in brain slices as determined by autoradiography*

Treatment of the newborn

rats

\begin{tabular}{lcc}
\cline { 2 - 3 } Brain area & Control & Anoxia \\
\hline Cerebellum & $150 \pm 10$ & $202 \pm 6$ \\
Hippocampus & $100 \pm 15$ & $180 \pm 10$ \\
Striatum & $110 \pm 17$ & $170 \pm 17$ \\
Thalamus & $80 \pm 15$ & $107 \pm 21$ \\
Hypothalamus & $90 \pm 7$ & $98 \pm 18$ \\
Neocortex & $85 \pm 12$ & $76 \pm 14$
\end{tabular}

* Brain slices from control and 20-min anoxic rats were incubated in the presence of $0.4 \mu \mathrm{m}\left[{ }^{14} \mathrm{C}\right]$ bilirubin and processed for autoradiography. The results are expressed as number of radioactive grains per $10,000 \mu \mathrm{m}^{2}$ and are the means \pm SEM for at least 15 serial sections.

\section{DISCUSSION}

The experimental model we have selected to render the newborn rats anoxic has the advantage of having been previously used for studying the alterations in brain energy metabolism and blood parameters $\left(\mathrm{pH}, \mathrm{pCO}_{2}, \mathrm{pO}_{2}\right.$, glucose, lactate, etc.) promoted by a 20-min anoxic episode (11,37-39). Furthermore, the period of 20-min anoxia, although producing considerable biochemical and circulatory changes, has a high survival index (11), thus allowing the study of the brain bilirubin levels during recovery from anoxia and the neonatal development period.

The results reported herein indicate that 1) Postnatal anoxia induces a significant, temporary increase (up to $200 \%$ with respect to control values) in whole-brain bilirubin levels during anoxia and short-term recovery in all the newborn rats exposed to nitrogen atmosphere at 18-24 h postpartum (Fig. 1). Treatment of the newborn rats with a single dose of sulfixosazole before subjecting them to 20 -min anoxia markedly enhances bilirubin accumulation by the brain of the anoxic rats, whereas an injection of bilirubin slows down the decrease in brain bilirubin concentrations observed after the first $30 \mathrm{~min}$ of recovery (Table 2). These data, together with the autoradiographic localization of radioactive bilirubin in tissue sections from the brain of anoxia-treated rats (Fig. 2), strongly suggest that, as a result of anoxia, a displacement of unbound bilirubin from blood to the nervous tissue occurs. 2) A second rise in brain bilirubin levels was detected in a group of the newborn rats 3- to 6 days after exposure to anoxia (Table 1), when all other biochemical parameters altered by anoxia had already been restored to control values $(11,37,39)$. A relatively wide range of brain bilirubin concentrations was observed in the rats affected. 3) Autoradiographic localization of radiolabeled bilirubin following in vivo experiments suggests that bilirubin is preferentially accumulated in some areas of the newborn rat brain as a consequence of postnatal anoxia (Fig. 2). This, in turn, suggests that the brain bilirubin concentrations determined in the whole brain of the anoxic rats could be an underestimate of the actual levels of the pigment in local regions of the nervous tissue. Furthermore, the brain areas where bilirubin is accumulated preferentially, coincide roughly with those more frequently stained in bilirubin encephalopathy (19) and with those more severely damaged as a result of perinatal asphyxia (38). On the other hand, the brain regions where local, intense spots of radioactive bilirubin appear (i.e. choroid plexus, cerebral cortex) are related to the areas of higher incidence of intracerebral hemorrhages during the perinatal period $(20,35)$.

The brain bilirubin levels determined in the brain of control rats are similar to those previously described and probably reflect the albumin-bound bilirubin present in the blood vessels (34). The possible pathological relevance of brain bilirubin levels remains to be established when we have a better knowledge of local bilirubin concentrations and of the mechanisms of bilirubin neurotoxicity.

Lucey et al., (24), in monkeys, and Chen et al. $(7,8)$, in rabbits, have reported that neonatal anoxia causes deposition of bilirubin in the brain (detected by histological techniques), only when superimposed to experimentally induced severe hyperbilirubinemia. Our findings indicate that postnatal anoxia, without concomitant hyperbilirubinemia, is able to promote bilirubin accumulation in the newborn brain.

The remarkable, transient rise in brain bilirubin levels observed during anoxia and the early recovery phase might be explained by the acidosis induced by anoxia. Blood $\mathrm{pH}$ declines by approximately $0.6 \mathrm{pH}$ units in newborn rats subjected to 20 min anoxia (37). A decreased $\mathrm{pH}$ has been shown to enhance the in vitro interaction of bilirubin with liposomes (12) and human erythrocyte membranes (33), as well as bilirubin incorporation into culture cells (28) and brain slices (18). In agreement with these data, we have found that bilirubin interaction with rat brain synaptosomal membranes is markedly augmented as $\mathrm{pH}$ decreases (unpublished work). A decline in blood pH, increasing the interaction of bilirubin with the brain cellular membranes, could displace bilirubin from its binding to albumin, allowing pigment accumulation in the brain. This process should be favored, as it has been confirmed in our experiments, in the presence of drugs such as sulfixosazole (known to displace bilirubin from albumin) as well as in neonatal hyperbilirubinemia, in which the free pigment concentration in blood is augmented (6). In addition, Diamond and Schmid (10) have reported that acidosis induced by infusion of diluted $\mathrm{HCl}$ increases brain bilirubin levels in guinea pigs. Neonatal acidosis has been put forward as an important risk factor for the development of bilirubin encephalopathy $(4,43)$, and appears frequently in the clinical reports of newborns diagnosed with kernicterus (19). Furthermore, comparing the changes in blood $\mathrm{pH}$ of 1-day-old rats during 20-min anoxia and the following recovery (37) with those of brain bilirubin levels depicted in Figure 1, a clear inverse relationship between these parameters appears. Wennberg and Ahlfors (42), discussing the possible role of acidosis in inducing kernicterus, have pointed out that arterial blood $\mathrm{pH}$ might not reflect the actual tissue acidosis adequately and that in asphyxiated newborns the $\mathrm{pH}$ gradient between different brain regions and central arterial blood might be large. In fact, a better inverse relationship ( $p<0.01$ and $<0.05$, respectively) than with blood $\mathrm{pH}$ is obtained when comparing brain bilirubin levels with lactate concentrations in brain or in cerebrospinal fluid during 20 -min anoxia and the early phase of recovery (37).

Although all these data are consistent with a role for acidosis in promoting accumulation of unbound bilirubin in the brain, it is not possible to disregard an accumulation of albumin-bound bilirubin in the nervous tissue as a result of either a reversible opening of the blood-brain barrier induced by anoxia (17) or the occurrence of a vasogenic brain edema (26). Levine et al. (21) have recently reported that albumin-bound bilirubin is able to penetrate the brain when the blood-brain barrier is reversibly opened by means of an hyperosmolar infusion.

On the other hand, the increase in brain bilirubin levels that takes place 3-6 days after the anoxic episode (Table 1) might reflect the occurrence of intracerebral hemorrhages of different size and location during the period of anoxia and/or recovery, as a result of in situ catabolism up to bilirubin of the heme group of the hemoglobin of the extravasated blood.

Although this conclusion remains speculative and needs to be confirmed, a number of data are consistent with this explanation. First, it seems to be established that perinatal asphyxia gives rise to intracerebral bleeding in human neonates (especially in prematures) probably as a consequence of alterations in the cerebral blood flow $(22,40)$. Recently, Zhukova and Hallman (45) have reported that experimental perinatal asphyxia in rats promotes intracerebral bleeding, most of all in the periventricular areas, 
the thalamus, and the choroid plexus. In the latter area, we have detected, in the in vivo autoradiographic experiments, intense, local spots of radioactive bilirubin (see Fig. $2 B$ ) that could be an indication of the occurrence of an hemorrhage, as extravasated blood contains bilirubin, free or bound to albumin. Bada et al. (2) and Goddard et al. (16) have also detected a high incidence of bleedings in the choroid plexus. The intraventricular and periventricular hemorrhages are the most frequent in human newborns, particularly in preterm neonates $(20,35)$, although bleeding occurs as well in the region of the cerebral cortex (41), where we have also found local accumulation of radiolabeled bilirubin following anoxia (Fig. $2 C$ ).

Second, the presence of macrophages in areas of brain hemorrhages has been observed $(5,45)$. Macrophages have the enzymes required to catabolize the heme group up to bilirubin (30). Roost et al. (32) have reported the occurrence of heme oxygenase activity in cerebral cortex, choroid plexus, and arachnoid following experimental subarachnoid bleeding. The changes in the composition of the cerebrospinal fluid after such hemorrhages have been studied in human adults (13). The hemoglobin level reaches a maximum $36 \mathrm{~h}$ after bleeding and then disappears gradually, whereas bilirubin reaches its maximum concentration 3-4 days after the subarachnoid hemorrhage. This delay is similar to that observed in our experiments. Furthermore, a relationship between the occurrence of intracerebral bleeding (detected by computer-assisted tomography), and a xantochromathic cerebrospinal fluid has been reported in human neonates (20). Recently, Lucey (23) has suggested a role for intracerebral bleeding in the pathogenesis of kernicterus.

Finally, the preferential accumulation of bilirubin in different areas of the brain (see Table 3 and Fig. 2), as well as the relatively wide range of brain bilirubin levels detected 3-6 days after the anoxic episode (Table 1), might be interesting factors in an attempt to explain the varying degrees of neurological damage (ranging from severe cerebral palsy and mental retardation to minor neurological impairment) associated with both kernicterus and perinatal asphyxia. The relevance of the different factors that might account for such regional distribution of bilirubin (regional differences in cerebral blood flow, $\mathrm{pH}$, or preferential interaction of bilirubin with the membranes of some areas or cell types of the brain) remain to be established.

Acknowledgments. The authors thank Mr. Martín Caballero for the computer image analysis of the autoradiograms. Mrs. Mercedes López and Mr. Rogelio Sánchez are gratefully acknowledged for their excellent technical assistance.

\section{REFERENCES}

1. Ackerman BD, Dyer GI, Leydorf MM 1970 Hyperbilirubinemia and kernicterus in small premature infants. Pediatrics 45:918

2. Bada HS, Hajjar W, Chua C, Summer DS 1979 Noninvasive diagnosis of neonatal asphyxia and intraventricular hemorrhage by Doppler ultrasound. J Pediatr 95:775

3. Brodersen R 1974 Competitive binding of bilirubin and drugs to human serum albumin studied by enzymatic oxidation. J Clin Invest 54:1353

4. Brodersen R 1980 Bilirubin transport in the newborn infant, reviewed with relation to kernicterus. J Pediatr $96: 349$

5. Bronson RT, Meadow PE, Strauss WM 1980 Morphology and morphogenesis of cerebral ring hemorrhages in anemic monkeys. Acta Neuropathol (Berl) $51: 155$

6. Cashore WJ, Oh W 1982 Unbound bilirubin and kernicterus in low-birthweight infants. Pediatrics 69:481

7. Chen H, Lien I, Lu T 1965 Kernicterus in newborn rabbits. Am J Pathol 46:331

8. Chen H, Lin C, Lien I 1966 Ultrastructural studies in experimental kernicterus. Am J Pathol 48:683

9. Cowger ML 1973 Bilirubin encephalopathy. In: Gaull GE (ed) Brain Disfunction. Plenum Press, New York, pp 265-293

10. Diamond I, Schmid R 1966 Experimental bilirubin encephalopathy. The mode of entry of bilirubin $-{ }^{14} \mathrm{C}$ into the central nervous system. J Clin Invest 45:678

11. Duffy TE, Kohle SJ, Vannucci RC 1975 Carbohydrates and energy metabolism in perinatal rat brain: relation to survival in anoxia. J Neurochem 24:271

12. Eriksen EF, Danielsen H, Brodersen R 1981 Bilirubin-liposome interaction. J Biol Chem 256:4269

13. Fishman RA 1980 Cerebrospinal fluid in disease of the nervous system WB Saunders Company, Philadelphia

14. Fuxe K, Calza L, Benfenati F, Zini I, Agnati LF 1983 Quantitative autoradiographic localization of ${ }^{3} \mathrm{H}$-imipramine binding sites in the brain of the rat: relationship to ascending 5-hydroxytryptamine neuron systems. Proc Natl Acad Sci USA 80:3836

15. Gartner LM, Snyder RN, Chabon RS, Bernstein J 1970 Kernicterus: high incidence in premature infants with low serum bilirubin concentrations. Pediatrics 45:906

16. Goddard J, Lewis RM, Armstrong DL, Zeller RS 1980 Moderate, rapidly induced hypertension as a cause of intraventricular hemorrhage in the newborn beagle model. J Pediatr 96:1057

17. Johansson B 1974 Blood-brain barrier dysfunction in acute arterial hypertension after papaveine-induced vasodilatation. Acta Neurol Scand 50:573-580

18. Kashiwamata S, Suzuki F, Semba RK 1980 Affinity of young rat cerebral slices for bilirubin and some factors influencing its transfer to the slices. Japan. J Exp Med 50:303

19. Kim MH, Yoon JJ, Sher J, Brown AK 1980 Lack of predictive indices in Kernicterus: a comparison of clinical and pathologic factors in infants with or without kernicterus. Pediatrics 66:852

20. Leblanc R, O'Gorman A 1980 Neonatal intracranial hemorrhage-a clinical and serial computerized tomographic study. J Neurosurg 53:642

21. Levine RL, Fredericks WR, Rapoport SI 1982 Entry of bilirubin into the brain due to opening of the blood-brain barrier. Pediatrics 69:255-259

22. Lou HC 1980 Perinatal hypoxic-ischemic brain damage and intraventricular hemorrhage-a pathogenetic model. Arch Neurol 37:585

23. Lucey JF 1982 Bilirubin and brain damage-a real mess. Pediatrics 69:381

24. Lucey JF, Hibbard E, Behrman RE, Esquivel de Gallardo FO, Windle WF 1964 Kerniecterus in asphyxiated newborn Rhesus monkeys. Exp Neurol 9:43

25. Mustafã MG, King TE 1970 Binding of bilirubin with lipid. J Biol Chem 245:1084

26. Myers RE 1977 In: Gluck L (ed) "Intrautercina Asphyxia and the Developing Brain." Year Book Medical Publishers, Inc., Chicago, pp 37-97

27. Myers RE 1979 A unitary theory of causation of anoxia and hypoxia brain pathology. In: Fahn C, Davis JN, Rowland LP (eds) Cerebral Hypoxia and its Consequences. Advances in Neurology. vol 26. Raven Press, New York, pp 195-213

28. Nelson T, Jacobsen J, Wennberg RP 1974 Effect of $\mathrm{pH}$ on the interaction of bilirubin with albumin and tissue culture cells. Pediatr Res 8:963

29. Odell GB 1981 Neonatal hyperbilirubinemia. Grune and Stratton, Inc, New York

30. Raffin SB, Woo CH, Roost KT 1974 Intestinal absorption of hemoglobiniron-heme cleavage by mucosal heme oxygenase. J Clin Invest 54:1344

31. Ritter DA, Kenny JD, Norton J, Rudolph AJ 1982 A prospective study of free bilirubin and other risk factors in the development of kernicterus in premature infants. Pediatrics 69:260

32. Roost KT, Pimstone NR, Diamond I 1972 The formation of cerebrospinal fluid xantochromia after subarachnoid hemorrhage. Enzymatic conversion of hemoglobin to bilirubin by the arachnoid and choroid plexus. Neurology 22:973

33. Sato M, Kashiwamata S 1983 Interaction of bilirubin with human erythrocyte membranes. Biochem J 210:489

34. Sawasaki Y, Yamada N, Nakajima H 1976 Developmental features of cerebellar hypoplasia and brain bilirubin levels in a mutant (Gunn) rat with hereditary hyperbilirubinemia. J Neurochem 27:577

35. Schrumpf JD, Shering S, Killpack S, Brody JP, Hirata T, Mednick JP 1980 Correlation of early neurologic outcome and CT findings in neonatal brain hypoxia and injury. J Comput Assist Tomogr 4:445

36. Turkel SB, Miller CA, Guttenberg ME, Moynes DR, Hodgman JE 1982 A clinical pathological reapparaisal of kernicterus. Pediatrics 69:267

37. Vannucci RC, Duffy TE 1976 Carbohydrate metabolism in fetal and neonatal rat brain during anoxia and recovery. Am J Physiol 230:1269

38. Vannucci RC, Plum F 1975 Pathophysiology of perinatal hypoxic-ischemic brain damage. In: Gaull GE (ed) Biology of Brain Disfunction. Vol 3. Plenum Press, New York, pp 1-45

39. Vannucci SJ, Vannucci RC 1980 Glycogen metabolism in neontal rat brain during anoxia and recovery. J Neurochem 34:1100

40. Volpe JJ 1979 Cerebral blood flow in the newborn infant: Relation to hypoxicischemic brain injury and periventricular hemorrhage. J Pediatr 94:170

41. Volpe JJ, Pasternak JF 1977 Pasasagittal cerebral injury in neonatal hypoxicischemic encephalopathy: clinical and neuroradiologic features. J Pediatr 91:472

42. Wennberg RP, Ahlfors CE 1982 Free bilirubin is of importance. Pediatrics 70:658

43. Wennberg RP, Ahlfors CE, Rasmussen LF 1979 The patochemistry of kernicterus. Early Hum Dev 3/4:353

44. Young WS, Kuhar MJ 1979 A new method for receptor autoradiography: ${ }^{3} \mathrm{H}-$ opioid receptors in rat brain. Brain Res 179:255

45. Zhukova TP, Hallman M 1982 Effect of acute perinatal asphyxia on development of the lung and brain in the rat. Biol Neonate 41:183 